American Journal of Infectious Diseases 3 (4): 169-176, 2007

ISSN 1553-6203

(C) 2007 Science Publications

\title{
Sexual Risk Intervention In Multiethnic Drug And Alcohol Users
}

\author{
${ }^{1}$ Deborah L. Jones, ${ }^{2}$ Stephen M. Weiss, ${ }^{3}$ Ndashi Chitalu, \\ ${ }^{2}$ Olga Villar, ${ }^{2}$ Mahendra Kumar,${ }^{3}$ Violet Bwalya, ${ }^{2}$ Maureen Mumbi \\ ${ }^{1}$ Barry University, Miami Shores, Florida, \\ ${ }^{2}$ University of Miami Miller School of Medicine, Miami, Florida, \\ ${ }^{3}$ University of Zambia School of Medicine, Lusaka, Zambia
}

\begin{abstract}
An estimated 38.6 million persons globally are living with HIV, of whom over 1.1 million reside in Zambia. Of the 2 million cases in the US, 64\% of new cases among women are among African Americans. Alcohol and drug use represents a significant risk factor for HIV transmission among both Zambians and African Americans. In addition, gender dynamics in both the US and Zambia promote transmission. This study examines two interventions targeting HIV risk behavior among HIV positive substance users, women in Miami, USA (the New Opportunities for Women (NOW) Project) and men in Lusaka, Zambia (the Partner Project). The study compares the efficacy of these two culturally tailored sexual behavior interventions provided in group and individual session formats. US and Zambian participants increased sexual barrier use and reduced substance-related sexual risk. Comparatively greater gains were made by higher risk Zambian males than US females in both group and individual conditions. Among lower risk participants, women in the group condition achieved and sustained the greatest comparative risk reductions. Results suggest that cost effective group HIV transmission risk reduction interventions for multiethnic individuals can be successfully implemented among both female and male drug and alcohol users in multinational settings.
\end{abstract}

Key Words: Sexual Behavior, HIV, Zambia, Women, Men, Substance Use

\section{INTRODUCTION}

Despite educational and behavioral interventions and HIV testing programs, heterosexual transmission of HIV in the United States continues to increase and most HIV positive women were infected by their primary male partners ${ }^{[1-2]}$. Similarly, the majority of HIV infection in sub-Saharan Africa occurs in marital and cohabiting relationships ${ }^{[3-4]}$. Typically, condom use increases following a seropositive diagnosis or intervention, but is not sustained over 6 months ${ }^{[5-7]}$ and couples do not protect the uninfected partner ${ }^{[8]}$.

Effective safer sex interventions require a complex set of changes in a variety of behaviors. These changes include assessing and accepting sexual barriers, adhering to their use, and both sexual partners making significant changes in their sexual practices. As sexual transmission is the primary mode of infection, increasing communication about safer sex ${ }^{[9-10]}$ is essential to containing the virus in both sub-Saharan Africa and the US.

Alcohol and drugs are significant barriers to effective communication, and the effects of drug and alcohol use on sexual risk behavior and HIV transmission have been well documented in the US ${ }^{[11-}$ ${ }^{17]}$ and Sub-Saharan Africa ${ }^{[18-24]}$. The physiological effects of alcohol and drugs are barriers to condom negotiation ${ }^{[21]}$ and may exacerbate the perception of implied infidelity by the promoter of condom use or their partner ${ }^{[24]}$, resulting in domestic violence ${ }^{[19-26]}$. Clearly, those persons regularly combining drugs and alcohol with sex represent a high risk population in need of intervention.

Globally, an estimated 4.1 million people were newly infected with HIV in 2005, bringing the total number to 38.6 million persons living with HIV, of whom over 24.5 million reside in sub-Saharan Africa [27]. Zambia, a sub-Saharan country of 10.2 million persons, has been particularly hard-hit by the HIV

Corresponding Author: Deborah Jones, Ph.D., Barry University, 11300 NE $2^{\text {nd }}$ Ave., Miami Shores, Fl., 33161 USA, telephone 305899 4576, fax 3058993279 
pandemic, with prevalence rates of $17 \%$ among adults and as high as $30 \%$ among women in antenatal clinics in Lusaka ${ }^{[28]}$, the capital city (1.1 million estimated infections nationwide ${ }^{[27]}$ ). HIV in Zambia is predicted to reduce national productivity, decrease access to education and increase infant mortality to 82 per 1,000 live births ${ }^{[28]}$.

Zambia, a culturally diverse population with 5 distinct languages, 73 dialects and 72 ethnicities, is fairly typical of African societies in terms of social, political and economic gender inequity. Men are the primary sexual decision-makers ${ }^{[29]}$ and are in a position of dominance over their female counterparts, many having a mistress, using the services of a prostitute, or polygamous. Women are expected to ask their male partners for money to feed themselves and their children, for money or gifts in exchange for sex, and for permission to work and keep the money they earn ${ }^{[27]}$. The need to target HIV seropositive men in risk reduction interventions has been documented in a variety of African populations ${ }^{[29-34]}$.

In the US, there were an estimated 2 million new cases nationwide in $2005^{[27]}$, with many new cases occurring among minorities. Although African Americans account for less than $12 \%$ of the US population, they account for $50 \%$ of all HIV/AIDS cases diagnosed, and account for $64 \%$ of all cases among women ${ }^{[35]}$. Geographically, Florida ranks second in the US for newly reported HIV and AIDS cases, with higher rates than the national average among heterosexuals, women and African Americans [36]. The need to target HIV seropositive women has been widely noted ${ }^{[37-38]}$.

Sexual risk reduction interventions in the US that include sexual "education" ${ }^{[39-40]}$, skill training ${ }^{[41-42]}$, reproductive desires ${ }^{[43-44]}$, and sexual negotiation skills ${ }^{[43-46]}$, have been found to increase sexual barrier use among women. Interventions in Zambia to control the spread of HIV include encouraging generationconcordant coupling, reducing number of sexual partners, stage-based behavioral counseling promoting use and availability of male and female condoms, controlling other STDs, and encouraging Voluntary Counseling and Testing ${ }^{[47]}$.

Our previous research in both the US and Zambia found multi-session group and individual sexual behavior interventions to be effective among HIV seropositive women ${ }^{[43-44]}$ and men ${ }^{[38]}$. These group cognitive behavioral interventions emphasize and increase self-efficacy by providing opportunity to model behaviors and practice during sessions. Sessions provide skills such as cognitive re-framing, problem- and emotion-focused coping and assertiveness, while promoting attitude and behavioral change and increased self-efficacy and collective efficacy ${ }^{[48-49]}$.

This study compares two high risk seropositive drug and alcohol using populations drawn from the New Opportunities for Women (NOW) Project in Miami, USA and the Partner Project in Lusaka, Zambia on primary and secondary prevention issues. The study examines the impact of gender and culture on the efficacy of these two culturally tailored sexual risk reduction interventions in a gender-specific format ${ }^{[50]}$.

\section{MATERIALS AND METHODS}

Study design: The NOW Project was a multisite randomized study (Miami, US and Lusaka, Zambia) that recruited 549 Zambian women between January 2001 and May 2004; the Partner Project is a randomized study that recruited 420 Zambian couples between May 2002 and March 2006. The following analyses were conducted utilizing data derived from HIV seropositive alcohol and drug abusing US women and Zambian men as of October 20, 2006.

Participant intervention and examination protocol: Prior to participant recruitment, Institutional Review Board and Ethics Committee approvals were obtained in accordance with the provisions of the US Department of Health and Human Services regarding the conduct of research. Study candidates were recruited from local hospitals, community health centers and nongovernmental organizations. Due to potential emotional distress, participants testing positive within the previous two weeks were excluded. All participants were screened for eligibility, provided informed consent prior to enrollment, completed a baseline assessment and were randomized to one of two conditions, group or individual intervention. Due to ethical considerations regarding HIV transmission, no control, usual care or standard of care conditions were included in this study ${ }^{[38]}$. The primary reason for ineligibility was no current sexual partner or no sexual activity within the last month. All participants received monetary compensation for their time and travel.

\section{Intervention Group Conditions NOW and Partner Projects: The NOW Project group condition was manualized and developed from feedback from pilot studies with multicultural women, and has been described in earlier literature ${ }^{[38]}$. The Partner Project group condition was created following requests from male partners of NOW Project participants for a male}


version of the intervention and has also been described ${ }^{[44]}$. Sessions were developed and culturally adapted from men's focus groups conducted in the US and Zambia. Men in the Partner Project participated in men's groups while their female partners attended time matched women's groups.

Both the NOW and Partner Project's group interventions emphasized participation and experimentation with sexual barrier products and provided an opportunity for practice, feedback, and reinforcement of sexual risk reduction strategies. The Projects employed closed, structured behavioral change interventions limited to ten participants. Each of the three monthly two-hour sessions supported group cohesion and skill building in a supportive environment utilizing communication techniques, negotiation skills, and experiential/interactive skill training to expand and reframe perceptions of barrier use and to increase selfefficacy and skill mastery. Material was presented utilizing the conceptual model of the theory of reasoned action and planned behavior ${ }^{[51]}$. Facilitators were gender matched RNs, LPNs and health care staff trained in the administration of each condition.

The intervention and accompanying videos were developed in English and translated into Zambian local languages (Nyanja and Bemba) using African actors. The correct methods of barrier use, commonly asked questions and sexual negotiation scenarios were presented and discussed. After each session, participants were provided with a one-month supply of male and female condoms (sessions 1-3; visits 4-5) and vaginal lubricants (gels and suppositories; sessions 2-3; visits 4-5). Participants were strongly encouraged to use condoms with the vaginal lubricants at all times.

Intervention Individual Condition NOW Project: The individual condition in the NOW Project provided participants with time-matched information in a traditional health education individual format with a health educator. Sessions included information on HIV/STD transmission, hierarchical counseling and skill training to facilitate product use, videos, written materials on instructions for use, and supplies of male and female condoms and vaginal lubricants.

Intervention Individual Condition Partner Project: The individual intervention in the Partner Project provided a single group session that summarized the content of all three sessions. Male participants then attended time-matched sessions during which health related videos were shown. Participants were provided with supplies of male and female condoms and vaginal lubricants.

Assessments: The following assessment measures were utilized.

Demographic Questionnaire: This questionnaire included data collection on age, religion, nationality, ethnicity, educational level, employment status, residential status, HIV serostatus [date of HIV infection (if known), mode of infection with HIV], current or previous drug use/abuse, participation in drug treatment programs, marital status/current partner status, living situation, number of children and serostatus.

Sexual Activities Questionnaire: This 55-item scale was adapted from the Sexual Risk Behavior Assessment Schedule (SERBAS ${ }^{[52]}$ ). Responses indicated the frequency of heterosexual sexual intercourse (vaginal, oral, and anal) with both primary partners (most frequent sexual relations) and nonprimary partners (any other male partners). The questionnaire also assessed sexual barrier use, HIV status of the partner(s), known sexual practices of the partner, and alcohol or drug use prior to the initiation of sexual activity.

Alcohol and Drug Use and Needles Questionnaire: (current use, frequency, amount) was measured by a modified 22 item questionnaire was adapted to assess levels and frequency of alcohol, tobacco and drug use in the last 3 months/since the last interview and age at first use.

Coping: Coping strategies were measured by a revised version of the Brief COPE ${ }^{[53]}$, a 38-item revised version of the COPE specifically tailored to persons living with HIV/AIDS. For the purposes of the present study, the behavioral disengagement subscale, which targets alcohol and drug use, was utilized. Items are rated from 1 (I haven't been doing this at all) to 4 (I've been doing this a lot). Alpha reliabilities for the Brief COPE exceeded minimum standards in the validation sample $(\alpha=.80)$. Possible scores ranged from 2 to 8 for each subscale, with higher scores indicating greater use of the coping strategy.

\section{Participants:}

Miami: Participants $(\mathrm{n}=187)$ were HIV seropositive women with histories of alcohol and drug abuse (see Table 1). The majority was African American (73\%), with a mean age of 39 and a year 11 education. Most women were unmarried $(61 \%)$ and unemployed $(74 \%)$ with children (78\%), living below the poverty level $(51 \%)$. Many had been in drug (44\%) and alcohol $(26 \%)$ treatment and some relied on selling drugs (5\%) and prostitution (13\%) for income. 
Table 1: Demographic Characteristics of NOW and Partner Participants

\begin{tabular}{|c|c|c|c|c|}
\hline \multirow{2}{*}{ Characteristics } & \multicolumn{2}{|c|}{ NOW Participants } & \multicolumn{2}{|c|}{ Partner Participants } \\
\hline & $N$ & $\%$ & $N$ & $\%$ \\
\hline NOW Project & 187 & 100 & - & - \\
\hline Partner Project & - & - & 303 & 100 \\
\hline \multicolumn{5}{|l|}{ Ethnicity (Zambian) } \\
\hline Bemba & - & - & 56 & 30 \\
\hline Ngoni/Nsenga/Tumbaka & - & - & 60 & 32 \\
\hline Tonga/Mambwe/Namwanya & - & - & 30 & 16 \\
\hline Other & - & - & 41 & 22 \\
\hline \multicolumn{5}{|l|}{ Ethnicity (United States) } \\
\hline African American & 221 & 73 & - & - \\
\hline Haitian & 12 & 4 & - & - \\
\hline Hispanic & 27 & 9 & - & - \\
\hline Caucasian & 24 & 8 & - & - \\
\hline Other & 24 & 8 & - & - \\
\hline \multicolumn{5}{|l|}{ Marital Status } \\
\hline Married & 115 & 61 & 300 & 99 \\
\hline HIV+ Children & 26 & 14 & 30 & 10 \\
\hline Children & 176 & 94 & 282 & 93 \\
\hline
\end{tabular}

Table 2: Mean Risk Behavior score

\begin{tabular}{cccc}
\hline Miami/Zambia & Condition Assignment & Mean & Standard Deviation \\
Miami & Group & 5.94 & 4.13 \\
Raseline & Individual & 5.67 & 3.69 \\
Risk Behavior & Group & 4.78 & 4.14 \\
6 months & Individual & 4.40 & 4.30 \\
Risk Behavior & Group & 4.16 & 4.63 \\
12 months & Individual & 5.10 & 2.36 \\
Zambia & Group & 4.41 & 2.19 \\
Risk Behavior & Individual & 4.45 & 2.33 \\
Baseline & Group & 4.16 & 2.25 \\
Risk Behavior & Individual & 4.10 & 1.87 \\
6 months & Group & 3.90 & 2.15 \\
Risk Behavior & Individual & 3.70 & \\
12 months & & & \\
\hline
\end{tabular}

Zambia: Participants ( $\mathrm{n}=303$ ) were HIV seropositive Zambians with histories of alcohol and drug abuse (see Table 1$)$. The majority was Bemba $(30 \%)$, with a mean age of 37 ; most of the men were married (99\%) and unemployed (74\%). All were living below the poverty level. The average level of educational attainment was completion of the $12^{\text {th }}$ grade, ranging from primary $(39 \%)$ to secondary education $(59 \%)$ and some college $(2 \%)$. None of the sample had ever been treated for drug or alcohol problems.

Statistical analyses: This study used a repeated measures design with experimental arm (group, individual, gender) as the between-subjects factor and time (baseline and post-intervention) as the withinsubjects factor. Correlations are reported as Pearson's $r$ statistics; repeated measures between arms are reported as F statistics and effects of time on the overall sample are reported as t tests, all comparisons used an alpha (2tailed) of 0.05 .

The variable 'Risk Behavior' is a total score representing an individual's risky behavior as it pertains to sex, alcohol, and drugs. Components of the Risk Behavior score were items on the Sexual Activities Questionnaire, COPE, Alcohol, Drug, and Needle Use 
Questionnaire, and, Demographic Questionnaire identified as measures of risk behavior. To compute this variable, the identified items were recoded so that responses indicating the highest risk were given values ranging from 1-4 according to level of risk of activity and low risk responses were recoded as 0 . These recoded items were summed to compute an overall Risk Behavior score.

\section{RESULTS}

Sexual Risk Behavior: Mean values for both sites are outlined in Table 2.

US Women: Among NOW participants $(\mathrm{n}=187)$, there was no significant difference between conditions in overall risk behavior $(F[2,116]=1.312, p=.273)$; both conditions reduced their level of risk at six months and twelve months. The group condition maintained the greatest reductions over 12 months.

Zambian Men: Among Partner participants $(\mathrm{n}=303)$, there was no significant difference by condition over time $(F[2,130]=.167, p=.683)$; both conditions reduced their level of risk at six months and continued to decrease their level of risk at 12 months.

High and Low Risk Takers: Reduction in risk behavior by level of risk was examined by comparing high and low sexual risk takers within condition over time at both sites combined. When both projects were compared, reductions in risk were significantly different among low risk takers by condition over time $(F[4,219]=5.60, p<.001)$ and among high risk takers by project over time $(F[4,219]=4.68, p=.001)$ as illustrated in Figures 1 and 2. The intervention effects revealed that the greater comparative reductions were made by men in the Partner Project than women in the NOW Project, and both Partner conditions did sustain greater comparative reductions in risk behavior among high risk takers. Among low risk takers, only NOW women in the group condition achieved and sustained reductions in comparative risk.

\section{DISCUSSION}

This study compared two interventions targeting high risk seropositive drug and alcohol using populations in the US and Zambia. The results of this study support the use of gender specific culturally tailored group interventions in both locations to reduce sexual risk behavior. In addition, results suggest that risk takers may benefit from differing types of interventions targeting specific levels of risk behavior. Finally, results highlight the importance of male involvement in interventions targeting risk reduction among seropositive couples.

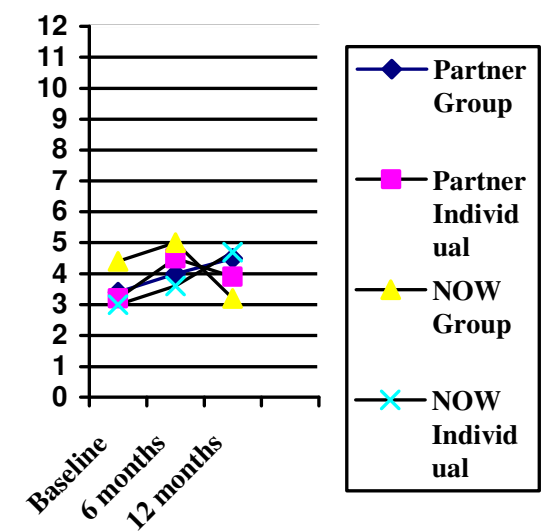

Fig.1: Low Risk Takers between Projects

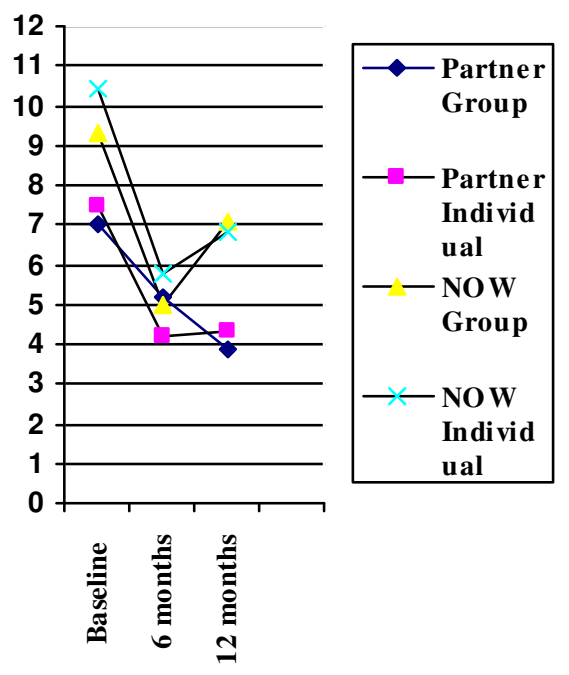

Fig. 2: High Risk Takers between Projects

This study supports our previous research in both the US and Zambia with HIV seropositive women ${ }^{[43-44]}$ and men ${ }^{[38]}$. While the projects differed in their impact on varying levels of risk taking among participants, both projects showed reduction of risk.

Interestingly, in the US, risk reduction was decreased and sustained in women in the group condition, in Zambia, low risk taking men did not decrease their level of risk. In fact, risk among these men was sustained at their original levels, which suggests that there may be a level of risky behavior that 
represents a normative standard or floor effect in the population.

In contrast, among high risk takers, Zambian men decreased their level of risk in both single and multiple levels of the intervention. Sessions providing skills such as cognitive re-framing, problem- and emotion-focused coping and assertiveness appear to be associated with behavioral change in both the US and Zambia sample. Among high risk takers in the US, although women decreased their level of risk across the duration of the twelve month project, they did not sustain risk reductions at the same low levels over time. This type of rebound effect in US women was less pronounced than in earlier interventions, in which condom use increases are not sustained over 6 months ${ }^{[5-7]}$.

The intervention appears to have been successful in supporting sexual partners to make significant changes in their sexual practices. Both men and women at both sites responded favorably to the intervention, although those engaging in higher levels of risk showed the greatest improvement. This may be due to the increased potential for risk reduction among those engaging in the highest risk.

The results of this study were limited by the same issues that make the outcome so interesting: the differences between populations. Clearly, low income drug abusing women in urban Miami differ from low income alcohol abusing men in urban Lusaka. Women are not able to require their male partners to use condoms while men are sexual decision makers. In addition, participants differed between locations in the time since diagnosis, and more recently diagnosed men in Lusaka may have been more highly motivated to change their behavior than women earlier diagnosed. Further research could be conducted to evaluate the potential to effect sustained behavioral change among African men who are long term survivors with HIV.

Culturally, the intervention appears to be successful among men and women in diverse settings. Results suggest that cost effective group HIV transmission risk reduction interventions for multiethnic individuals can be successfully implemented among both female and male drug and alcohol users in multinational settings. Clearly, male involvement in educational and behavioral interventions to reduce transmission of HIV by partners is needed in US ${ }^{[1-2]}$ and African populations ${ }^{[29-34]}$. This is especially important in settings in which men act are the primary sexual decision-makers or domestic violence may occur.

\section{ACKNOWLEDGEMENT}

Financial support: National Institute of Child Health and Development, grant no. R24HD43613, and the National Institute of Mental Health, grant no. R01MH63630. In addition, support was provided from the International American University for the initial presentation of this research at the Symposium on HIV AIDS \& Recreational Drugs, India, November 6-7 2006.

We would like to acknowledge the members of our research teams at the University Of Miami Miller School Of Medicine, Barry University, the University of Zambia School of Medicine, the Teaching Hospital in Lusaka, community sites providing referrals in the US and Zambia and the women and men participating in this research.

\section{REFERENCES}

1. Amaro, H., 2000. On the margin: Power and women's HIV risk reduction strategies. Sex Roles, 42(7-8): 723-749

2. O'Leary, A., 2000. Women at risk for HIV from a primary partner: Balancing risk and intimacy. Annual Review of Sexual Research, 11: 191-234.

3. Hira, S.K., P.J. Feldblum, J. Kamanga, G. Mukelabai, S.S. Weir, J.C. Thomas, 1997. Condom and nonoxynol-9 use and the incidence of HIV infection in serodiscordant couples in Zambia. International Journal of STD AIDS, 8: 243-50.

4. McKenna, S.L., G.K. Muyinda, D. Roth, M. Mwali, N. Ng'andu, A. Myrick, A., et al., 1997. Rapid HIV testing and counseling for voluntary testing centers in Africa. AIDS, 11 (suppl 1): S103S110.

5. DiClemente, R.J., G.M. Wingood, 1995. A randomized controlled trial of an HIV sexual riskreduction intervention for young African-American women. JAMA, 25(274): 1271-6.

6. Greenberg, J., M. Hennessy, R. MacGowan, D. Celetano, V. Gonzalez, N. Van Devanter, J.Lifshay, 2000. Modeling intervention efficacy for high-risk women. The WINGS Project. Eval. Health Prof., 23(2):123-48.

7. Rugpao, S., S. Koonlertkit, S. Pinjaroen, W. Sinchai, A. Wongthanee, S. Sriplienchan, D. Celentano, C.S. Morrison, 2004. Patterns of male condom use and risky sexual behaviors in Thai couples receiving ongoing HIV risk reduction counseling. XV International AIDS Conference 2004, Bangkok, 11-16 July (abstract no. $\mathrm{ThPeC} 7408)$. 
8. Whitehead, S.J., S. Chaikummao, W. Uthaiworavit, S. Sumanapun, L.E. Markowitz, J.W. Tappero, C.A. McLean, 2004. HIV-discordant couples identified through screening for a clinical trial of microbicide safety: A chance to prevent HIV transmission. XV International AIDS Conference 2004, Bangkok, 11-16 July (abstract no.)

9. Kelly, J.A., S.C. Kalichman, 2002. Behavioral research in HIV/AIDS primary and secondary prevention: Recent advances and future directions. Journal of Consulting and Clinical Psychology, 20: 626-639.

10. Williams, S.P., P.S. Gardos, B. Ortiz-Torres, S. Tross, A.A. Ehrhardt, 2001. Urban women's negotiation strategies for safer sex with their male partners. Women Health, 33 (3-4):133-48.

11. Kalichman, S.C., D. Cain, A. Zweben, G. Swain, 2003. Sensation seeking, alcohol use and sexual risk behaviors among men receiving services at a clinic for sexually transmitted infections. Journal Stud. Alcohol, 64 (4): 564-9.

12. Wingood, G.M., R.J. DiClemente, 1998. The influence of psychosocial factors, alcohol and drug use on African American women's high risk sexual behavior. American Journal of Preventive Medicine, 15 (1): 54-9.

13. Dolezal, C., H.F. Meyer-Bahlburg, X. Liu, A.A. Ehrhardt, T.M. Exner, J.G. Rabkin, J.M. Gorman, K. Marder, Y. Stern, 1999. Longitudinal changes in sexual risk behavior among HIV+ and HIV- male injecting drug users. Am J Drug Alcohol Abuse. 25 (2): 281-303.

14. Dolezal, C., A.A. Ehrhardt, H.F. Meyer-Bahlburg, X. Liu, T.M. Exner, J.G. Rabkin, J.M. Gorman, K. Marder, Y. Stern, 1998. Sexual risk behavior changes among HIV+ and HIV-female injecting drug users over 4 years. Women's Health, 27 (4):1-17.

15. Hoffman, J.A., H. Klein, M. Eber, H. Crosby, 2000. Frequency and intensity of crack use as predictors of women's involvement in HIV-related sexual risk behaviors. Drug Alcohol Depend, 58 (3):227-36.

16. Essien, E.J., A.F. Meshack, R.J. Peters, G. Ogungbade, N.I. Osemene, 2005. Strategies to prevent HIV transmission among heterosexual African-American women. International Journal of Equity in Health, 4 (1): 4.

17. Essien, EJ, A.F. Meshack, R.J. Peters, G.O. Ogungbade, N.I. Osemene, 2005. Strategies to prevent HIV transmission among heterosexual African-American men. BMC Public Health, 5(1): 3.

18. Van der Straten, A., K.A. Vernon, K.R. Knight, C.A.Gomez, N.S. Padian, 1998. Managing HIV among serodiscordant heterosexual couples: Serostatus, stigma and sex. AIDS Care, 10 (5): $533-48$.
19. Van der Straten, A., R. King, O. Grinstead, E. Vittinghoff, A. Serufilira, S. Allen, 1998. Coercion, violence and HIV infection. AIDS and Behavior, 2: 61-73.

20. Murray, L.K., A. Haworth, K. Semrau, M. Singh, G.M. Aldrovandi, M. Sinkala, D.M. Thea, P.A. Bolton, 2006. Violence and abuse among HIVinfected women and their children in Zambia: a qualitative study. J Nerv Ment Dis. 194 (8): 610-5.

21. Abrahams, N., R. Jewkes, R. Laubscher, M. Hoffman, 2006. Intimate partner violence: prevalence and risk factors for men in Cape Town, South Africa. Violence Vict. 21 (2): 247-64.

22. Koenig, M.A., T. Lutalo, F. Zhao, F. Nalugoda, N. Kiwanuka, F. Wabwire-Mangen, G. Kigozi, N. Sewankambo, J. Wagman, D. Serwadda, M. Wawer, R. Gray, 2004. Coercive sex in rural Uganda: prevalence and associated risk factors. Soc Sci Med. 58 (4): 787-98.

23. Jewkes, R., J. Levin, L. Penn-Kekana, 2002. Risk factors for domestic violence: findings from a South African cross-sectional study. Soc Sci Med. 55 (9): 1603-17.

24. Wingood, G.M., R.J. DiClemente,.1997. The effects of an abusive primary partner on the condom use and sexual negotiation practices of African American women. American Journal of Public Health, 87: 1016-8.

25. Simoni, J.M. T. Ming, 2002. Abuse, health locus of control, and perceived health among HIV-positive women. Health Psychology, 21: 89-93.

26. Wingood, G.M., R.J. DiClemente, 1996. HIV sexual risk reduction interventions for women: A review. American Journal of Preventive Medicine, 12: 209-17.

27. UNAIDS, 2006. Executive Summary. 2006 Report on the Global AIDS Epidemic. Retrieved January 31, 2007, from http://www.unaids.org/bangkok2004/GAR2004>ht $\mathrm{ml} /$ ExecSummar

28. Central Statistical Office, 2002. Zambia Demographic and Health Survey. Central Statistical Office, Republic of Zambia.

29. Roth, D.L., K.E. Stewart, O.J. Clay, A. van der Straten, E. Karita, S. Allen, 2001. Sexual practices of HIV discordant couples in Rwanda: Effects of a testing and counseling program for men. International Journal of STD \& AIDS, 12: 181188. 
30. Sow, S., 1999. Enhancing men's participation and responsibilities for HIV in Africa, International Congress on AIDS in Southern Africa, Lusaka, Zambia, 13 September

31. Mitchell, K., S. Nakamanya, A. Kamali, J.A. Whitworth, 2002. Exploring the community response to a randomized controlled HIV/AIDS intervention trial in rural Uganda. AIDS Education \& Prevention, 14: 207-16.

32. Bwanika, V., D. Muteguya, M. Nakanjakko, A. Seeta-Nazigo, 2004. Assessing men's knowledge and attitude towards microbicides. Microbicides 2004, London, 28-31 March (abstract no. 02474).

33. Rwabukwali, C. B., J.W. McGrath, R.A. Salata, S.A.Rundall, D. Akurut, 2004. Anticipated acceptability of a vaginal microbicide among men attending the Mulago STD clinic in Kampala, Uganda. Microbicides 2004, London, 28-31 March (abstract no. 02131).

34. Smith, D., K. Chillag, L. Paxton, P.H. Kilmarx, 2004. High levels of comprehension and willingness to participate among women and men in Botswana. Microbicides 2004, London, 28-31 March (abstract no. 02677).

35. Centers for Disease Control \& Prevention, 2004. Sexually transmitted disease surveillance 2002. Department Of Health and Human Services, CDC, National Center for HIV, STD, and TB Prevention, Division of STD Prevention.

36. Florida Department of Health, 2002. Florida Annual Report/Epidemioloigcal Profile, Florida Department of Health.

37. Jones, D., S.M. Weiss, R.M. Malow, M. Ishii, J. Devieux, H. Stanley,

38. A. Cassells, J.N. Tobin, E. Brondolo, A. LaPerriere, J. Efantis-Potter, M.J. O'Sullivan, N. Schneiderman, 2001. A Brief Sexual Barrier Intervention for Women Living with AIDS: Acceptability, Use and Ethnicity. Journal of Urban Health, 78: 593-604.

39. Jones, D., D. Ross, S.M. Weiss, G. Bhat, N. Chitalu, 2005. Influence of partner participation on sexual risk behavior reduction among HIV-positive Zambian women. Journal of Urban Health, 82: 92100.

40. Magnani, R.J., A.M. Karim, L.A. Weiss, K.C. Bond, M. Lemba, G.T. Morgan, 2002. Reproductive health risk and protective factors among youth in Lusaka, Zambia. J Adolesc Health. 30 (1): 76-86.
41. Woog, V., 2003. Annotated bibliography on HIV/AIDS and youth in sub-Saharan Africa. Occasional Report, 9. New York: The Alan Guttmacher Institute.

42. Malow, R.M., D. Ziskind, D.L. Jones, 2000. Use of female controlled microbicidal products for HIV risk reduction. AIDS Care, 12(5): 581.

43. Van Devanter, N., 1999. Prevention of sexually transmitted diseases: the need for social and behavioral science expertise in public health departments. Am J Public Health.

44. Jones, D.L., S.M Weiss, G.J. Bhat, D.A. Feldman, V. Bwalya, D. Budash, 2004. A Sexual Barrier Intervention for HIV+/- Zambian Women: Acceptability and Use of Vaginal Chemical Barriers. Journal of Multicultural Nursing and Health, 10: 27-31.

45. Jones, D.L., G.J. Bhat, S.M. Weiss, D.A. Feldman, V. Bwalya, 2006. Influencing Sexual Practices Among HIV Positive Zambian Women. AIDS Care, 18 (6): 629-34.

46. Sheeran, P., C. Abraham, S. Orbell, S., 1999. Psychosocial correlates of heterosexual condom use: A meta-analysis. Psychological Bulletin, 125: 90-132.

47. Melendez, R.M., S. Hoffman, T. Exner, C.S. Leu, A.A. Ehrhardt, 2003. Intimate partner violence and safer sex negotiation: effects of a gender-specific intervention. Arch Sex Behav, 32 (6): 499-511.

48. Central Statistical Office, 2002. ANC Sentinel Surveillance of HIV/Syphilis Trends in Zambia 1994-2002. Central Statistical Office, Zambia.

49. Lazarus, R.S., S. Folkman, 1984. Stress Appraisal and Coping. New York, Springer Publishing Co.

50. Forsythe, C.J., B. Compas, 1987. Interaction and cognitive appraisals of stressful events and coping. Cognitive Behavior Therapy, 11: 473-485.

51. Exner, T.M., S.L. Dworkin, S. Hoffman, A.A. Ehrhardt, 2003. Beyond the male condom: the evolution of gender-specific HIV interventions for women. Annu Rev Sex Res, 14: 114-36.

52. Albarracin, D., B.T. Johnson, M. Fishbein, P.A. Muellerleile, 2001. Theories of reasoned action and planned behavior as models of condom use: a meta-analysis. Psychol Bull, 127 (1): 142-61

53. Meyer-Bahlberg, H.F.L., A.A. Ehrhardt, T.M. Exner, R.S. Gruen, 1990. Sexual Risk Behavior Assessment Schedule: Adult (SERBAS-A-DF-4) Manual

54. Carver, C., M. Scheier, J.D. Weintraub, 1989. Assessing coping strategies: A theoretically based approach. Journal of Personality and Social Psychology, 56: 267-283. 